\title{
High expression of endothelial progenitor cell-induced angiogenic markers is associated with bile acid levels in HCC
}

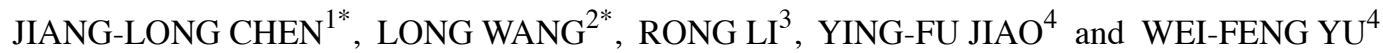 \\ ${ }^{1}$ Department of General Surgery, Children's Hospital of Shanghai, Shanghai Jiao Tong University, Shanghai 200062; \\ ${ }^{2}$ Anesthesia and Operation Center, Chinese PLA General Hospital, Beijing 100853; ${ }^{3}$ Department of Pathology, \\ Eastern Hepatobiliary Surgical Hospital, Second Military Medical University, Shanghai 200433; \\ ${ }^{4}$ Department of Anesthesiology, Ren Ji Hospital, Shanghai Jiao Tong University, \\ Shanghai 200127, P.R. China
}

Received January 8, 2020; Accepted June 2, 2020

DOI: $10.3892 / \mathrm{ol} .2020 .11815$

\begin{abstract}
Endothelial progenitor cell (EPC)-induced angiogenesis activity is enhanced in hepatocellular carcinoma (HCC); however, the contributing factors remain unknown. The present study aimed to investigate the factors influencing the number of EPCs and circulating progenitor cells (CPCs), as well as the expression levels of vascular endothelial growth factor receptor 2 (VEGFR-2) and CD34, in patients with HCC. The expression levels of VEGFR-2 and CD34 were assessed in $72 \mathrm{HCC}$ tumor and matched adjacent tissue microarrays by immunohistochemistry. The associations between VEGFR-2 or CD34 expression in tumors, clinicopathological characteristics and overall survival rates were analyzed. The number of EPCs and CPCs were analyzed in the peripheral blood of patients with HCC. In this study, high expression levels of VEGFR-2 and CD34 were detected in the tumor tissues of 41 (56.9\%) and $44(61.1 \%)$ patients, respectively. VEGFR-2 expression was significantly associated with tumor size $(\mathrm{P}<0.001)$, bile acid level $(\mathrm{P}=0.014)$ and $\alpha$-fetoprotein level $(\mathrm{P}=0.011)$. However, $\mathrm{CD} 34$ expression was associated with tumor size $(\mathrm{P}=0.009)$, recrudescence $(\mathrm{P}<0.001)$ and bile acid $(\mathrm{P}=0.009)$. Next, the expression levels of VEGFR-2 and CD34 in tumor and adjacent tissues were compared according to the bile acid level. VEGFR-2 and CD34 expression levels were both higher in the high bile acid group, whereas expression levels of the markers were higher in adjacent tissues compared with tumor tissues. Kaplan-Meier curve analysis identified that patients with low CD34 expression had a longer overall survival compared with
\end{abstract}

Correspondence to: $\mathrm{Dr}$ Wei-Feng $\mathrm{Yu}$, Department of Anesthesiology, Ren Ji Hospital, Shanghai Jiao Tong University, $160 \mathrm{Pu}$ Jian Road, Pudong New, Shanghai 200127, P.R. China

E-mail: ywf808@yeah.net

${ }^{*}$ Contributed equally

Key words: hepatocellular carcinoma, bile acid, endothelial progenitor cells, vascular endothelial growth factor receptor-2, CD34 patients with high $\mathrm{CD} 34$ expression $(\mathrm{P}=0.029)$. Multivariate analysis also indicated that both VEGFR-2 $(\mathrm{P}=0.020)$ and CD34 $(\mathrm{P}=0.035)$ were independent prognostic risk factors. Moreover, flow cytometry demonstrated that the number of EPCs and CPCs was negatively related with the bile acid levels in patients with HCC. In conclusion, in patients with $\mathrm{HCC}$, bile acid promotes EPC-induced angiogenesis. Furthermore, EPCs and CPCs may be activated by bile acid in tumors but are more so in adjacent tissues.

\section{Introduction}

Angiogenesis, the formation of new vascular structures, is essential for tumor growth and metastasis $(1,2)$. The degree of angiogenesis is a marker of diagnosis and prognosis in several human solid tumors (3-5). Endothelial progenitor cells (EPCs) have the potential to migrate, proliferate and differentiate into vascular or lymphatic endothelial cells, contributing to angiogenesis in ischemic diseases and tumor progression $(6,7)$.

Hepatocellular carcinoma (HCC) is one of the most prevalent tumor types and the second leading cause of cancer-related mortality in China (8). HCC is a highly angiogenic tumor, and the degree of angiogenesis correlates directly with prognosis $(9,10)$. Due to vigorous angiogenesis, HCC has a high incidence of early postoperative in situ or distant site recurrence, leading to a poor long-term prognosis (11). Previous studies have reported that EPCs contribute to angiogenesis in HCC (12-14). The number of EPCs is also known to be positively correlated with the invasive stages of HCC (15). Furthermore, HCC metastasis progression is inhibited by reducing the EPC population in an orthotopic liver cancer model (16). Pro-angiogenesis factors, such as vascular endothelial growth factor (VEGF) and platelet-derived growth factor, are highly expressed in human HCC tissues, and EPCs are considered to participate in this process (17). Therefore, elucidating the interactions between HCC pathophysiological changes and EPCs is critical for developing new therapeutic options.

Bile acid levels are increased in most patients with HCC, due to tumor progression $(18,19)$. Previous studies have revealed that disruption of the bile acid balance is associated 
with the development of liver diseases $(18,20)$. Moreover, bile salt may function as a survival agonist and potential carcinogen, inducing chemoresistance in $\operatorname{HCC}(21,22)$. Another study reported that tauroursodeoxycholic acid, a type of bile acid, promoted blood vessel repair by recruiting vasculogenic progenitor cells $\left(\mathrm{CD} 34^{+}\right)(23)$ Additionally, it has been demonstrated that EPCs are activated in the bone marrow by VEGF and migrate to the site of tumor angiogenesis $(24,25)$. The effects of VEGF are primarily mediated via the VEGF receptor-2 (VEGFR-2) in endothelial cells (26-28). However, the mechanisms underlying the contribution of EPC recruitment to tumor cell metastasis are complicated, and the relationship between bile acid levels and EPC-induced angiogenesis remains unknown. Thus, the present study detected VEGFR-2 and CD34 expression levels in HCC tumors, and the relationship between the bile acid levels and EPC number was subsequently analyzed.

\section{Materials and methods}

Patients, tissue samples and peripheral blood. The present study obtained 72 pairs of tumor and matched adjacent tissues all from patients (median age, 54; age range, 33-72 years; 60 males and 12 females) with HCC who were undergoing curative resection at the Liver Surgery Department of Eastern Hepatobiliary Surgery Hospital (EHBH; Shanghai, China) between June 2013 and September 2013. According to the pathologist's judgment criteria, $<3 \mathrm{~cm}$ was classed as 'adjacent' to cancer tissue, $3-5 \mathrm{~cm}$ was classed as 'near' cancer tissue and $>5 \mathrm{~cm}$ was defined as 'distant' to cancer tissue. These tissues were used to construct tissue microarrays (TMAs) for immunohistochemical (IHC) analysis. All the patients were followed up for $\geq 5$ years, with a median follow-up period of 42 months (range, 1-76 months). Additionally, $500 \mu 1$ peripheral blood samples from 64 other patients with $\mathrm{HCC}$ were obtained before they had undergone curative resection. Clinicopathological characteristics, such as gender, age, tumor size, and bile acid, $\alpha$-fetoprotein (AFP) and total bilirubin levels, were obtained from the patient's medical records. The study was approved by the Committee of Research Ethical Research at EHBH (approval no. EHBH KY2018-1-019), and prior patient written informed consent was obtained from all enrolled patients.

TMA-IHC staining. All the samples were frozen at $-196^{\circ} \mathrm{C}$ in liquid nitrogen until further examination. The samples were fixed in $4 \%$ paraformaldehyde at room temperature for $24 \mathrm{~h}$ and were then embedded in paraffin. The samples embedded in paraffin for TMA were collected using needles (diameter, $1.5 \mathrm{~mm}$ ) from a section of tumors and matched adjacent tissues. TMAs were cut at $3 \mu \mathrm{m}$ using a manual rotary microtome (RM2235; Leica Microsystems, Inc). In total, one set of TMA was evaluated for VEGFR-2 expression, and another set was evaluated for CD34 expression. TMAs were deparaffinized in xylene, rehydrated via a graded alcohol series $(100,85$ and $75 \%$ ) and then peroxidase activity was blocked using $3 \% \mathrm{H}_{2} \mathrm{O}_{2}$ in methanol for $15 \mathrm{~min}$ at room temperature. For antigen retrieval, TMAs were boiled twice at $96^{\circ} \mathrm{C}$ under atmospheric pressure in citrate buffer (pH 6.0; cat. no. E673000; Sangon Biotech Co., Ltd.) for 5 min. Non-specific binding was blocked by 5\% goat serum (cat. no. E661003; Sangon Biotech Co., Ltd.) in PBS for $15 \mathrm{~min}$ at room temperature. After washing with PBS, the sections were incubated with primary antibodies (VEGFR-2: 1:1,000; cat. no. ab9530; Abcam; CD34: 1:100; cat. no. sc-74499; Santa Cruz Biotechnology, Inc.) for $1 \mathrm{~h}$ at room temperature and then at $4^{\circ} \mathrm{C}$ overnight. After washing, TMAs were incubated with a horseradish peroxidase-conjugated secondary antibody (1:1,000; cat. no. ab6789; Abcam) for $30 \mathrm{~min}$ at $37^{\circ} \mathrm{C}$, the color was developed by a $15 \mathrm{~min}$ incubation at room temperature with DAB solution (cat. no. E670033; Sangon Biotech Co., Ltd.) and then the sections were weakly counterstained with hematoxylin for $10 \mathrm{~min}$ at room temperature. Negative controls were included using the replacement of the primary antibody with PBS.

A single-blind method was set to evaluate the IHC results independently by a pathologist. The counting protocol was performed according to a previous report (29). CD34 and VEGFR-2 were counted in a microscopic field using a light microscope at $x 400$ magnification $\left(0.0156 \mathrm{~mm}^{2} /\right.$ field of view). In total, three different random areas were selected, the percentage score and intensity score were calculated and then the average score was calculated. The percentages of TMA-IHC positive cells were scored into four categories according to the staining intensity: 1 for $0-10 \%, 2$ for $10-40 \%, 3$ for $40-70 \%$ and 4 for $70-100 \%$. The TMA-IHC staining intensities were also scored into four grades: 1, 2, 3 and 4 , as aforementioned. The sum of the percentages and intensity scores was used as the final TMA-IHC staining score and was defined as follows: 1-3, low expression; and 4-8, high expression. The sample was assigned to each group according to the sum of the percentage score and the intensity score.

Flow cytometry. For flow cytometry analysis, a total of $500 \mu \mathrm{l}$ peripheral blood was collected from each patient with HCC. The blood samples were hemolyzed using $2 \mathrm{ml}$ ammonium chloride solution (STEMCELL Technologies, Inc.), vortexed and incubated at room temperature for $30 \mathrm{~min}$. Subsequently, the samples were washed in PBS and centrifuged at $500 \mathrm{x} g$ for $5 \mathrm{~min}$ at $4^{\circ} \mathrm{C}$, the supernatant was discarded and the remaining cells (peripheral blood mononuclear cells) were resuspended in PBS. The samples were then stained with monoclonal antibodies against CD34 (1:50; cat. no. 11-0349), CD133 (1:100; cat. no. 17-1338) and VEGFR-2 (1:50; cat. no. 12-5821) (all from Affymetrix; Thermo Fisher Scientific, Inc.) at $4^{\circ} \mathrm{C}$ for $1 \mathrm{~h}$. Next, the samples were subjected to two-dimensional side scatter-fluorescence histogram analysis using a FACS instrument (Beckman Coulter, Inc.). Data analyses were performed using Flow-Jo (version X) flow cytometry analysis software (FlowJo LLC).

Statistical analysis. All experiments were repeated three times. A $\chi^{2}$ test was used to compare the CD34 and VEGFR-2 immunostaining results in different clinical feature groups. Cox regression was used to conduct univariate and multivariate analyses of prognostic factors for survival. Overall survival (OS) curves were estimated using the Kaplan-Meier method and the log-rank test. Student's t-test was used to compare two sets of data. Linear regression was used to analyze the relationship between the bile acid level and EPC and CPC 


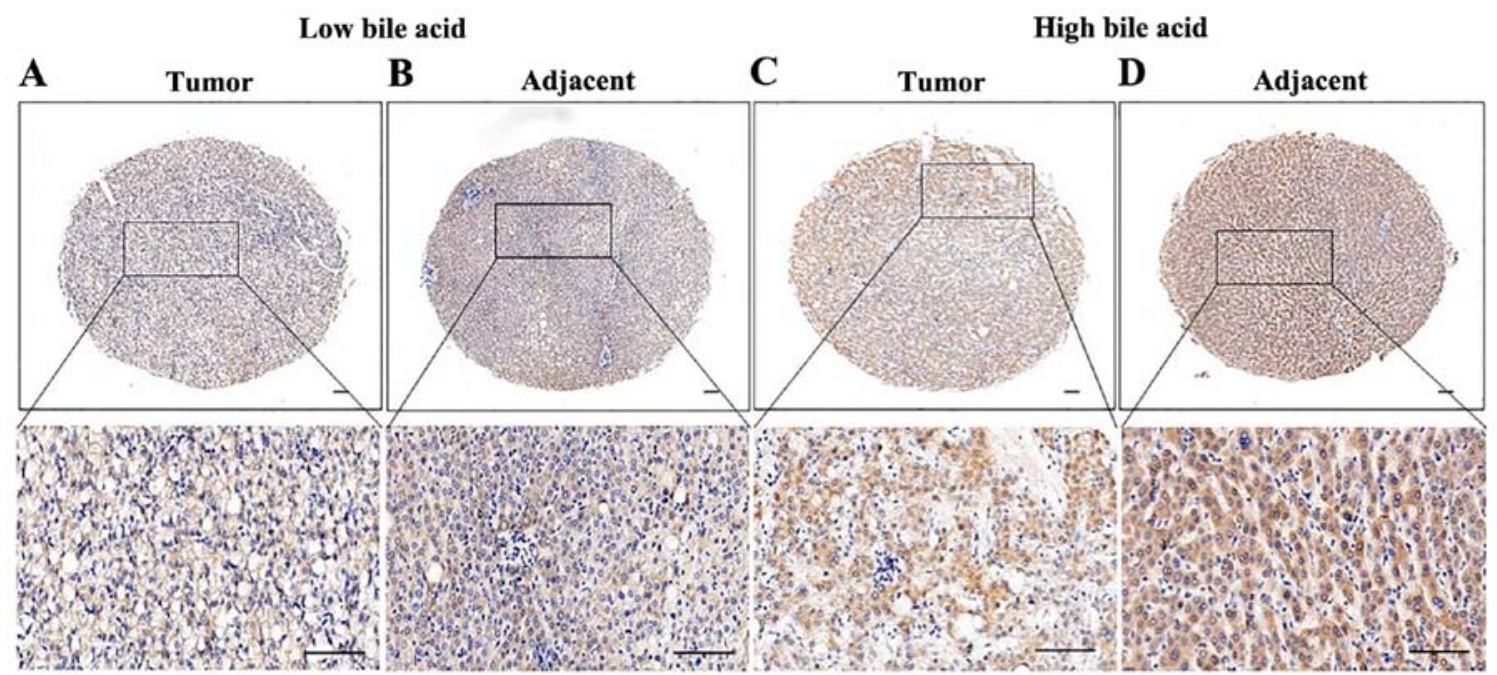

Figure 1. Immunohistochemical staining of VEGFR2 in patients with HCC tumors and matched adjacent tissues in low and high bile acid groups. (A) Immunohistochemical staining of VEGFR2 in patients with HCC tumor tissues in low bile acid group. (B) Immunohistochemical staining of VEGFR2 in matched adjacent tissues in low bile acid group. (C) Immunohistochemical staining of VEGFR2 in patients with HCC tumor tissues in high bile acid group. (D) Immunohistochemical staining of VEGFR2 in matched adjacent tissues in high bile acid group. Low bile acid, $\leq 10 \mu \mathrm{mol} / 1$; high bile acid, $>10 \mu \mathrm{mol} / 1$. Scale bar, $100 \mu \mathrm{m}$. VEGFR2, vascular endothelial growth factor receptor 2; HCC, hepatocellular carcinoma.

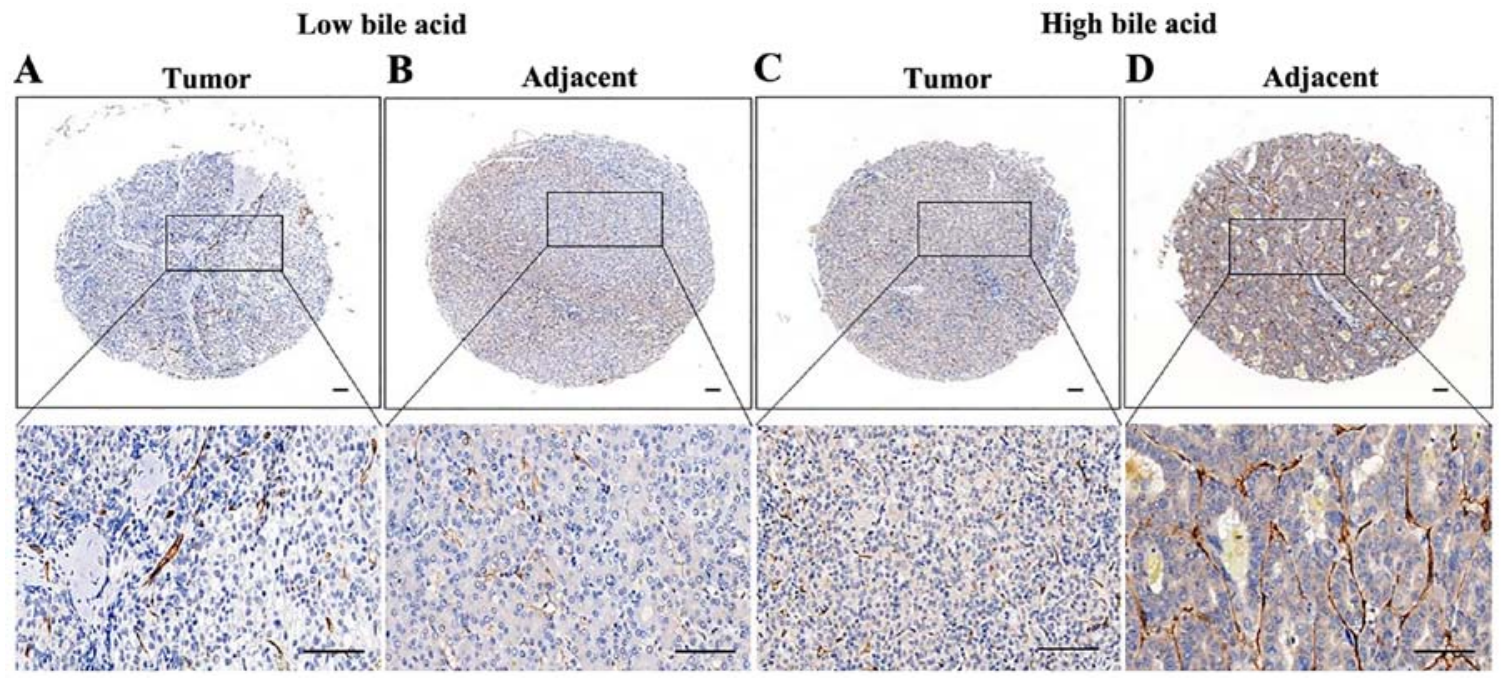

Figure 2. Immunohistochemical staining of CD34 in patients with HCC tumor and matched adjacent tissues in the low and high bile acid groups. (A) Immunohistochemical staining of CD34 in patients with HCC tumor tissues in low bile acid group. (B) Immunohistochemical staining of CD34 in matched adjacent tissues in low bile acid group. (C) Immunohistochemical staining of CD34 in patients with HCC tumor tissues in high bile acid group. (D) Immunohistochemical staining of CD34 in matched adjacent tissues in high bile acid group. Low bile acid, $\leq 10 \mu \mathrm{mol} / 1$; high bile acid, $>10 \mu \mathrm{mol} / 1$. Scale bar, $100 \mu \mathrm{m}$. HCC, hepatocellular carcinoma.

numbers. Data were analyzed using Stata Statistical Software (Release 13; StataCorp LLC). $\mathrm{P}<0.05$ was considered to indicate a statistically significant difference.

\section{Results}

VEGFR-2 and CD34 expression levels and clinicopathological characteristics. Among the 72 patients, 41 (56.94\%) and $44(61.11 \%)$ demonstrated high expression levels of VEGFR-2 and CD34, respectively. Representative IHC staining images of VEGFR-2 and CD34 are presented in Figs. 1 and 2. VEGFR-2 expression was found to be significantly associated with the tumor size $(\mathrm{P}<0.001)$, bile acid level $(\mathrm{P}=0.014)$ and AFP level $(\mathrm{P}=0.011$; Table I). The other clinical characteristics, including sex, age, HBV infection, TNM stage, pathological grade, recrudescence, liver cirrhosis, satellite nodules, venous invasion, Child-Pugh stage (30) and total bilirubin level, were not directly associated with the expression of VEGFR-2 (Table I). However, CD34 expression was significantly associated with the tumor size $(\mathrm{P}=0.009)$, recrudescence $(\mathrm{P}<0.001)$ and bile acid level $(\mathrm{P}=0.009)$. Other clinical characteristics, including sex, age, HBV infection, TNM stage, pathological grade, liver cirrhosis, satellite nodules, venous invasion, Child-Pugh stage, AFP level and total bilirubin level were not directly related to the expression of CD34 (Table II).

Comparison of VEGFR-2 and CD34 expression in tumor and matched adjacent tissue according to the bile acid level. 
Table I. Association between VEGFR-2 expression in tumor tissues and clinicopathological characteristics in patients with HCC $(n=72)$.

VEGFR-2

\begin{tabular}{|c|c|c|c|c|c|}
\hline Clinicopathological parameters & Number of cases $(\%)$ & Low $(\%)$ & High (\%) & $\chi^{2}$ & P-value \\
\hline \multicolumn{6}{|l|}{ Sex } \\
\hline Male & $60(83)$ & $24(77)$ & $36(88)$ & 0.012 & 0.91 \\
\hline Female & $12(23)$ & $7(23)$ & $5(12)$ & & \\
\hline \multicolumn{6}{|l|}{ Age, years } \\
\hline$\leq 50$ & $24(33)$ & $10(32)$ & $14(34)$ & 0.028 & 0.87 \\
\hline$>50$ & $48(67)$ & $21(68)$ & $27(66)$ & & \\
\hline \multicolumn{6}{|l|}{ HBV infection } \\
\hline Positive & $56(78)$ & $22(71)$ & $34(83)$ & 1.46 & 0.23 \\
\hline Negative & $16(22)$ & $9(29)$ & 7 (17) & & \\
\hline \multicolumn{6}{|l|}{ Tumor, cm } \\
\hline$\leq 5$ & $35(47)$ & $24(77)$ & $11(27)$ & 18.09 & $<0.001^{\mathrm{b}}$ \\
\hline$>5$ & $37(53)$ & $7(23)$ & $30(73)$ & & \\
\hline \multicolumn{6}{|l|}{ TNM stage } \\
\hline I-II & $25(35)$ & $11(35)$ & $14(34)$ & 1.06 & 0.30 \\
\hline III-IV & $47(65)$ & $20(65)$ & $27(66)$ & & \\
\hline \multicolumn{6}{|l|}{ Recrudescence } \\
\hline Yes & $38(53)$ & $15(48)$ & $23(56)$ & 0.42 & 0.52 \\
\hline No & $34(47)$ & $16(52)$ & $18(44)$ & & \\
\hline \multicolumn{6}{|l|}{ Liver cirrhosis } \\
\hline Yes & $49(68)$ & $20(65)$ & $29(71)$ & 0.31 & 0.58 \\
\hline No & $23(32)$ & $11(35)$ & $12(29)$ & & \\
\hline \multicolumn{6}{|l|}{ Satellites nodules } \\
\hline Yes & $43(60)$ & $16(52)$ & $27(66)$ & 1.49 & 0.22 \\
\hline No & $29(40)$ & $15(48)$ & $14(34)$ & & \\
\hline \multicolumn{6}{|l|}{ Venous invasion } \\
\hline Yes & $52(72)$ & $23(74)$ & $29(71)$ & 0.11 & 0.75 \\
\hline No & $20(28)$ & $8(26)$ & $12(29)$ & & \\
\hline \multicolumn{6}{|l|}{ Differentiation grade } \\
\hline Well & $21(29)$ & $13(42)$ & $8(20)$ & 4.79 & 0.091 \\
\hline Moderate & $29(40)$ & $9(29)$ & $20(49)$ & & \\
\hline Poor & $22(31)$ & $9(29)$ & $13(31)$ & & \\
\hline \multicolumn{6}{|l|}{ Child-Pugh stage } \\
\hline A & $25(35)$ & $10(32)$ & $15(37)$ & 0.15 & 0.70 \\
\hline $\mathrm{B}$ and $\mathrm{C}$ & $47(65)$ & $21(68)$ & $26(63)$ & & \\
\hline \multicolumn{6}{|l|}{ Bile acid, $\mu \mathrm{mol} / 1$} \\
\hline$\leq 10$ & $30(42)$ & $18(58)$ & $12(29)$ & 6.023 & $0.014^{\mathrm{a}}$ \\
\hline$>10$ & $42(58)$ & $13(42)$ & $29(71)$ & & \\
\hline \multicolumn{6}{|l|}{$\mathrm{AFP}, \mathrm{ng} / \mathrm{ml}$} \\
\hline$\leq 20$ & $34(47)$ & $20(65)$ & $14(34)$ & 6.53 & $0.011^{\mathrm{a}}$ \\
\hline$>20$ & $38(53)$ & $11(35)$ & $27(66)$ & & \\
\hline \multicolumn{6}{|l|}{ Total bilirubin, $\mu \mathrm{mol} / \mathrm{l}$} \\
\hline$\leq 21$ & $39(54)$ & $14(45)$ & $25(61)$ & 1.78 & 0.18 \\
\hline$>21$ & $33(46)$ & $17(55)$ & $16(39)$ & & \\
\hline
\end{tabular}

${ }^{\mathrm{a}} \mathrm{P}<0.05 ; \quad{ }^{\mathrm{b}}<0.001$. AFP, $\alpha$-fetoprotein; HCC, hepatocellular carcinoma; VEGF-2, vascular endothelial growth factor receptor 2 ; HBV, Hepatitis B. 
Table II. Correlation between CD34 expression and clinicopathological characteristics in patients with HCC (n=72).

\begin{tabular}{|c|c|c|c|c|c|}
\hline \multirow[b]{2}{*}{ Clinicopathological parameters } & \multirow[b]{2}{*}{ Number of cases (\%) } & \multicolumn{2}{|c|}{ CD34 } & \multirow[b]{2}{*}{$\chi^{2}$} & \multirow[b]{2}{*}{ P-value } \\
\hline & & Low $(\%)$ & High $(\%)$ & & \\
\hline \multicolumn{6}{|l|}{ Sex } \\
\hline Male & $60(83)$ & $22(79)$ & $38(86)$ & 0.75 & 0.39 \\
\hline Female & $12(17)$ & $6(21)$ & $6(14)$ & & \\
\hline \multicolumn{6}{|l|}{ Age, years } \\
\hline$\leq 50$ & $24(33)$ & $10(36)$ & $14(32)$ & 0.12 & 0.73 \\
\hline$>50$ & $48(67)$ & $18(64)$ & $30(68)$ & & \\
\hline \multicolumn{6}{|l|}{ HBV infection } \\
\hline Positive & $56(78)$ & $21(75)$ & $35(80)$ & 0.21 & 0.65 \\
\hline Negative & $16(22)$ & $7(25)$ & $9(20)$ & & \\
\hline \multicolumn{6}{|l|}{ Tumor, cm } \\
\hline$\leq 5$ & $35(47)$ & $19(68)$ & $16(36)$ & 6.79 & $0.009^{\mathrm{a}}$ \\
\hline$>5$ & $37(53)$ & $9(32)$ & $28(64)$ & & \\
\hline \multicolumn{6}{|l|}{ TNM stage } \\
\hline I-II & $25(35)$ & $12(43)$ & $13(30)$ & 1.34 & 0.25 \\
\hline III-IV & $47(65)$ & $16(57)$ & $31(70)$ & & \\
\hline \multicolumn{6}{|l|}{ Recrudescence } \\
\hline Yes & $38(53)$ & $6(21)$ & $32(73)$ & 18.07 & $<0.001^{\mathrm{b}}$ \\
\hline No & $34(47)$ & $22(79)$ & $12(27)$ & & \\
\hline \multicolumn{6}{|l|}{ Liver cirrhosis } \\
\hline Yes & $49(68)$ & $19(68)$ & $30(68)$ & 0.001 & 0.98 \\
\hline No & $23(32)$ & $9(32)$ & $14(32)$ & & \\
\hline \multicolumn{6}{|l|}{ Satellites nodules } \\
\hline Yes & $43(60)$ & $14(50)$ & $29(66)$ & 1.80 & 0.18 \\
\hline No & $29(40)$ & $14(50)$ & $15(34)$ & & \\
\hline \multicolumn{6}{|l|}{ Venous invasion } \\
\hline Yes & $52(72)$ & $18(64)$ & $34(77)$ & 1.44 & 0.23 \\
\hline No & $20(28)$ & $10(36)$ & $10(23)$ & & \\
\hline \multicolumn{6}{|l|}{ Differentiation grade } \\
\hline Well & $21(29)$ & $8(29)$ & $13(30)$ & 0.055 & 0.97 \\
\hline Moderate & $29(40)$ & $11(39)$ & $18(40)$ & & \\
\hline Poor & $22(31)$ & $9(32)$ & $13(30)$ & & \\
\hline \multicolumn{6}{|l|}{ Child-Pugh stage } \\
\hline A & $25(35)$ & $8(29)$ & $17(39)$ & 0.77 & 0.38 \\
\hline $\mathrm{B}$ and $\mathrm{C}$ & $47(65)$ & $20(71)$ & $27(61)$ & & \\
\hline \multicolumn{6}{|l|}{ Bile acid, $\mu \mathrm{mol} / 1$} \\
\hline$\leq 10$ & $30(42)$ & $17(61)$ & $13(30)$ & 6.84 & $0.009^{\mathrm{a}}$ \\
\hline$>10$ & $42(58)$ & $11(39)$ & $31(70)$ & & \\
\hline \multicolumn{6}{|l|}{ AFP, ng/ml } \\
\hline$\leq 20$ & $34(47)$ & $15(54)$ & $19(43)$ & 0.74 & 0.39 \\
\hline$>20$ & $38(53)$ & $13(46)$ & $25(57)$ & & \\
\hline \multicolumn{6}{|l|}{ Total bilirubin, $\mu \mathrm{mol} / 1$} \\
\hline$\leq 21$ & $39(54)$ & $13(36)$ & $26(57)$ & 0.041 & 0.84 \\
\hline$>21$ & $33(46)$ & $10(64)$ & $18(43)$ & & \\
\hline
\end{tabular}

${ }^{\mathrm{a} P}<0.01$; ${ }^{\mathrm{b}} \mathrm{P}<0.001$. AFP, $\alpha$-fetoprotein; HCC, hepatocellular carcinoma; HBV, Hepatitis B.

Previous analyses have revealed that both VEGFR-2 and CD34 Therefore, the expression levels of these two biomarkers in expression levels are associated with the bile acid level $(24,31)$. tumor and matched adjacent tissues were compared with the 
bile acid level. The expression levels of VEGFR-2 and CD34 were higher in tumors compared with matched adjacent tissues, but there was no difference between the high and low bile acid groups (VEGFR-2, $\mathrm{P}=0.96$, Table III; CD34, $\mathrm{P}=0.78$, Table IV). The score of VEGFR-2 ( $\mathrm{P}=0.044$; Table SI) was higher in the high bile acid group compared with that in the low bile acid group in the non-tumor adjacent tissues, while the score of $\mathrm{CD} 34(\mathrm{P}=0.020$; Table SII) was higher in the high bile acid group compared with that in the low bile acid group in both the tumor and matched adjacent tissues.

Comparison of the prognostic impact of VEGFR-2 and CD34 expression in tumor tissues. At the last follow up, $52.78 \%$ of all cases presented recurrence and mortality occurred in $44.44 \%$ cases. The OS of patients with high VEGFR-2 expression was decreased compared with patients with low VEGFR-2 expression, but this difference was not significant (29.73 months vs. 65.83 months, respectively; $\mathrm{P}=0.094$; Fig. 3). Additionally, patients with high CD34 expression had a significant difference in OS compared with patients with low CD34 expression in Kaplan-Meier curve analysis (28.30 months vs. 65.38 months, respectively; $\mathrm{P}=0.029$; Fig. 4).

Univariate and multivariate analyses of $\mathrm{OS}$ were performed in patients with HCC. Univariate analysis indicated that the TNM stage $(\mathrm{P}=0.030)$, recrudescence $(\mathrm{P}=0.048)$, VEGFR-2 $(\mathrm{P}<0.001)$ and $\mathrm{CD} 34(\mathrm{P}=0.005)$ were significantly associated with OS (Table V). Moreover, multivariate Cox regression analysis suggested that VEGFR-2 $(\mathrm{P}=0.020)$ and $\mathrm{CD} 34$ $(\mathrm{P}=0.035)$ were independent prognostic factors for $\mathrm{OS}$, while the TNM stage and recrudescence were not (Table V).

Comparison of the number of EPCs and circulating progenitor cells (CPCs) in peripheral blood cells of patients with HCC patients before surgery. As aforementioned, the expression levels of VEGFR-2 and CD34 were related to the bile acid level. Additionally, VEGFR-2 and CD34 expression levels were closely associated to the number of EPCs and CPCs. To determine the relationship between the bile acid level and the number of EPCs and CPCs, flow cytometry was performed on the peripheral blood of patients with HCC before curative resection. These data indicated that the number of EPCs and CPCs was reduced in the high bile acid group compared with the low bile acid group (Fig. 5A-D). However, only EPCs had a statistically significant difference $(\mathrm{P}=0.044$; Fig. $5 \mathrm{~B})$. Furthermore, EPC $(\mathrm{P}=0.005$; Fig. 5E) and $\mathrm{CPC}(\mathrm{P}=0.01$; Fig. 5F) numbers were negatively related to the bile acid levels, and the EPCs and CPCs demonstrated an undifferentiated bilirubin state in different groups (Fig. S1).

\section{Discussion}

Pathological angiogenesis is a crucial hallmark of cancer progression, including in HCC. Although the relationship between VEGFR-2 expression in tumors and clinicopathological characteristics has been extensively studied (32-34), the expression levels of VEGFR-2 and CD34 in both tumor tissues and adjacent tissues from patients with $\mathrm{HCC}$ remains elusive. The present results demonstrated that VEGFR-2 and CD34 expression levels were negatively related to $\mathrm{OS}$ in patients with HCC. Additionally, both expression markers were independent
Table III. High expression of vascular endothelial growth factor receptor 2 in hepatocellular carcinoma patient tumor and matched adjacent tissues in low and high bile acid groups.

\begin{tabular}{lcccc}
\hline Classification & Tumor & Adjacent & $\chi^{2}$ & P-value \\
\hline Low bile acid & 12 & 14 & & \\
High bile acid & 29 & 33 & 0.03 & 0.96 \\
\hline
\end{tabular}

Low bile acid, $\leq 10 \mu \mathrm{mol} / 1$. High bile acid, $>10 \mu \mathrm{mol} / 1$.

Table IV. High expression of CD34 in hepatocellular carcinoma patient tumor and matched adjacent tissues in low and high bile acid groups.

\begin{tabular}{lcccc}
\hline Classification & Tumor & Adjacent & $\chi^{2}$ & P-value \\
\hline Low bile acid & 13 & 11 & & \\
High bile acid & 31 & 30 & 0.077 & 0.78 \\
\hline
\end{tabular}

Low bile acid, $\leq 10 \mu \mathrm{mol} / 1$. High bile acid, $>10 \mu \mathrm{mol} / 1$.

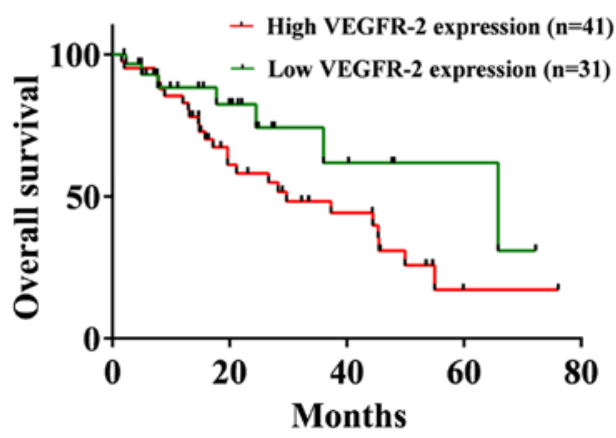

Figure 3. Kaplan-Meier survival analysis of VEGFR-2 expression in patients with HCC. Correlation between the prognosis of patients with HCC and tumor expression of VEGFR-2. Low bile acid, $\leq 10 \mu \mathrm{mol} / \mathrm{l}$; high bile acid, $>10 \mu \mathrm{mol} / 1$. $\mathrm{P}=0.094$. VEGFR-2, vascular endothelial growth factor receptor 2; HCC, hepatocellular carcinoma.

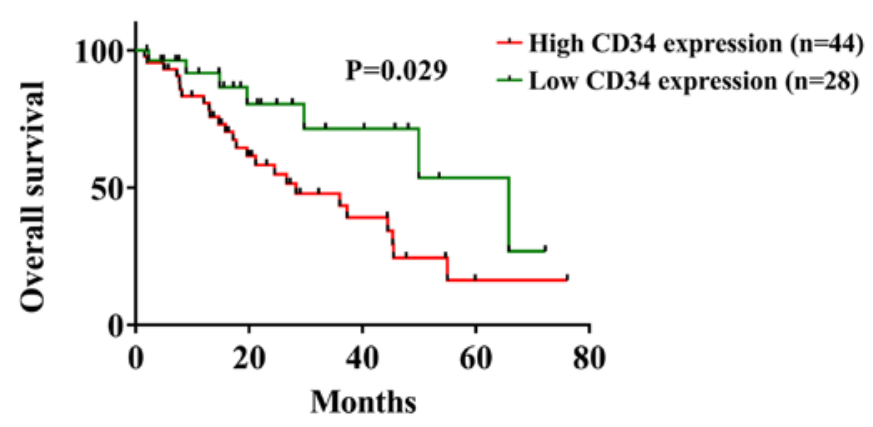

Figure 4. Kaplan-Meier survival analysis of CD34 expression in patients with HCC. Correlation between the prognosis of patients with HCC and tumor expression of CD34. Low bile acid, $\leq 10 \mu \mathrm{mol} / 1$; high bile acid, $>10 \mu \mathrm{mol} / 1$. HCC, hepatocellular carcinoma.

prognosis factors according to univariate and multivariate analyses. Huang et al (35) reported that high expression of 
Table V. Univariate and Multivariate analyses of prognostic factors for survival in hepatocellular carcinoma.

\begin{tabular}{|c|c|c|c|c|}
\hline \multirow[b]{2}{*}{ Variables } & \multicolumn{2}{|c|}{ Univariable } & \multicolumn{2}{|c|}{ Multivariable } \\
\hline & P-value & HR $(95 \% \mathrm{CI})$ & $\mathrm{P}$-value & HR $(95 \%$ CI $)$ \\
\hline \multicolumn{5}{|l|}{ Sex } \\
\hline Male and female & 0.24 & $0.53(0.18-1.54)$ & & \\
\hline \multicolumn{5}{|l|}{ Age, years } \\
\hline$\leq 50$ and $>50$ & 0.55 & $0.80(0.38-1.68)$ & & \\
\hline \multicolumn{5}{|l|}{ HBV infection } \\
\hline Positive and negative & 0.098 & $1.93(0.89-4.20)$ & & \\
\hline \multicolumn{5}{|l|}{ Tumor, cm } \\
\hline$\leq 5$ and $>5$ & 0.34 & $0.70(0.34-1.43)$ & & \\
\hline \multicolumn{5}{|l|}{ TNM stage } \\
\hline I-II and III-IV & $0.030^{\mathrm{a}}$ & $0.42(0.19-0.92)$ & 0.55 & $0.78(0.35-1.76)$ \\
\hline \multicolumn{5}{|l|}{ Recrudescence } \\
\hline Yes and no & $0.048^{\mathrm{a}}$ & $0.47(0.22-0.99)$ & 0.61 & $0.82(0.37-1.79)$ \\
\hline \multicolumn{5}{|l|}{ Liver cirrhosis } \\
\hline Yes and no & 0.37 & $0.72(0.35-1.48)$ & & \\
\hline \multicolumn{5}{|l|}{ Satellites nodules } \\
\hline Yes and no & 0.11 & $0.54(0.25-1.16)$ & & \\
\hline \multicolumn{5}{|l|}{ Venous invasion } \\
\hline Yes and no & 0.077 & $0.50(0.23-1.08)$ & & \\
\hline \multicolumn{5}{|l|}{ Differentiation grade } \\
\hline Well, Moderate and Poor & 0.065 & $0.51(0.24-1.04)$ & & \\
\hline \multicolumn{5}{|l|}{ Child-Pugh stage } \\
\hline $\mathrm{A}, \mathrm{B}$ and $\mathrm{C}$ & 0.90 & $1.05(0.52-2.11)$ & & \\
\hline \multicolumn{5}{|l|}{ Bile acid $(\mu \mathrm{mol} / \mathrm{l})$} \\
\hline$\leq 10$ and $>10$ & 0.58 & $1.22(0.61-2.42)$ & & \\
\hline \multicolumn{5}{|l|}{$\operatorname{AFP}(\mathrm{ng} / \mathrm{ml})$} \\
\hline$\leq 20$ and $>20$ & 0.14 & $1.77(0.84-3.72)$ & & \\
\hline \multicolumn{5}{|l|}{ Total bilirubin $(\mu \mathrm{mol} / \mathrm{l})$} \\
\hline$\leq 21$ and $>21$ & 0.20 & $1.59(0.79-3.21)$ & & \\
\hline \multicolumn{5}{|l|}{ VEGFR-2 } \\
\hline High and low expression & $<0.001^{\mathrm{c}}$ & $0.15(0.051-0.42)$ & $0.020^{\mathrm{a}}$ & $0.27(0.089-0.81)$ \\
\hline \multicolumn{5}{|l|}{ CD34 } \\
\hline High and low expression & $0.005^{\mathrm{b}}$ & $0.057(0.008-0.42)$ & $0.035^{\mathrm{a}}$ & $0.11(0.015-0.87)$ \\
\hline
\end{tabular}

${ }^{\mathrm{a}} \mathrm{P}<0.05 ;{ }^{\mathrm{b}} \mathrm{P}<0.01 ;{ }^{\mathrm{C}} \mathrm{P}<0.001$. AFP, $\alpha$-fetoprotein; HBV, Hepatitis B; VEGFR-2, vascular endothelial growth factor 2; HR, hazard ratio.

VEGFR-2 in HCC was related to a large tumor diameter, poor differentiation, high serum AFP levels, multifocal gross classification and $<5$ years of survival. Moreover, it was revealed that high VEGFR-2 expression and stage grouping with TNM classification were independent prognostic factors (35); these findings were consistent with the present results. VEGFR-2 is known to be a key target in anti-angiogenesis during anti-tumor treatment (36-38). Tsuji et al (39) revealed that CD34 expression in the capillaries and sinusoids of non-cancerous hepatic tissue was a risk factor for the multicentric recurrence of HCC. In the present study, it was found that CD34 expression in HCC tumor tissue was a risk factor for recurrence. Furthermore, the morphology of VEGFR-2- and CD34-positive cells in HCC tumors reported in previous studies were consistent with those in the current study (39-41).

VEGFR-2 and CD34 co-expression has previously been used as a characteristic marker of EPCs (42-44). Zahran et al (44) reported that EPCs were higher in patients with HCC compared with healthy controls, and increased levels of EPCs were associated with worse OS in HCC. EPCs present an undifferentiated bilirubin state in different groups (44), a finding that was corroborated by the present study. However, in the current study, the number of EPCs in the peripheral blood of patients with HCC was negatively related with the bile acid level. In addition, 
A

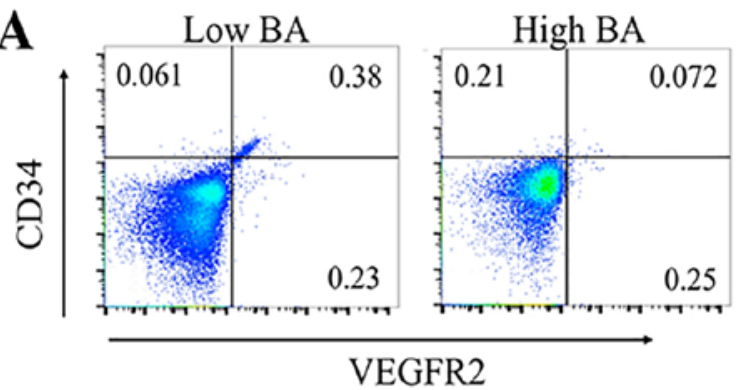

C

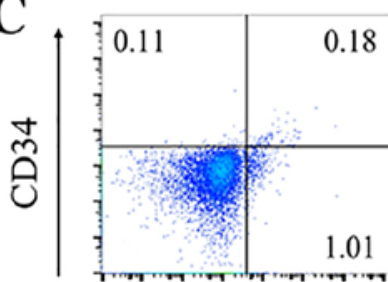

1.01

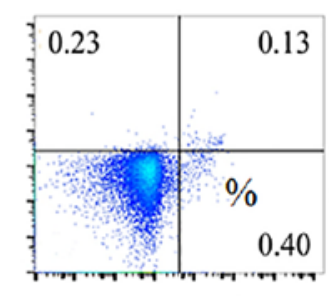

$\mathrm{CD} 133$

$\mathbf{E}$

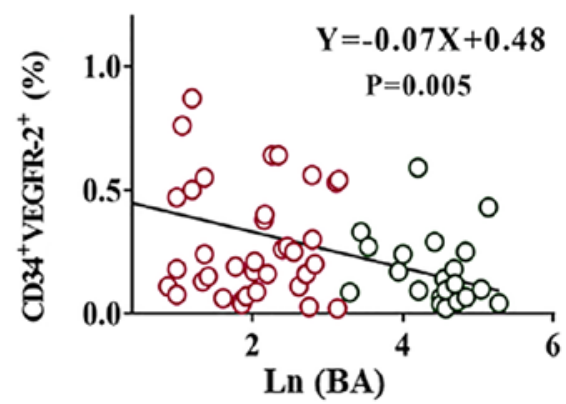

B

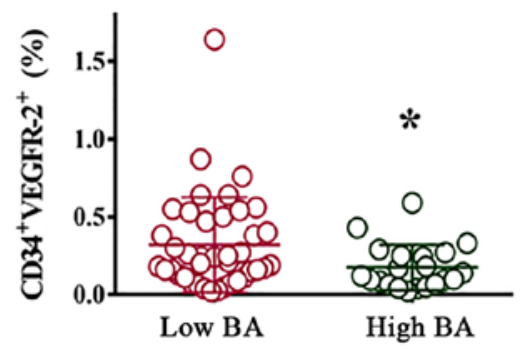

D
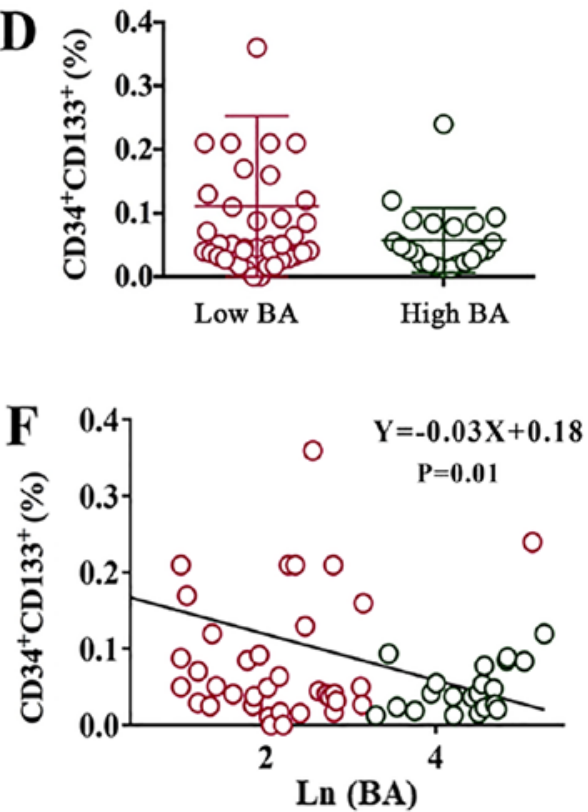

Figure 5. Serum BA level is negatively related to the percentage of circulating EPCs and CPCs in patients with HCC. (A) Flow cytometry gating strategy of EPCs (CD34+VEGFR-2+) in the mononuclear cells of peripheral blood between high-BA and low-BA groups. (B) Percentage of EPCs (CD34+VEGFR-2+) in the mononuclear cells of peripheral blood between the high-BA and low-BA groups. (C) Flow cytometry gating strategy of CPCs (CD34+CD133+) in the mononuclear cells of peripheral blood between high-BA and low-BA groups. (D) Percentage of CPCs (CD34+CD133+) in the mononuclear cells of peripheral blood between the high-BA and low-BA groups. Negative relationship between the percentage of (E) EPCs or (F) CPCs and Ln of serum BA. Low BA, $\leq 10 \mu \mathrm{mol} / 1$; high BA, $>10 \mu \mathrm{mol} / 1$. "P=0.044 vs. low BA. BA, bile acid; CPCs, circulating progenitor cells; EPCs, endothelial progenitor cells; VEGF-2, vascular endothelial growth factor receptor 2; Ln, natural logarithm.

VEGFR-2 and CD34 expression levels were increased in the high bile acid group. The cause of this contradiction may be that EPCs were activated into tumor cells from the peripheral blood in the high bile acid group. Zhu et al (42) revealed that various subgroups of bone marrow-derived cells exhibit synergistic effects of BM-derived $\mathrm{CD}^{-} 5^{+} \mathrm{CD} 133^{+}$and VEGFR $2^{+} \mathrm{CD} 133^{+}$ cells on $\mathrm{HCC}$ tumor progression at different stages, facilitate the recovery of bone marrow function and promote tumor growth.

In the present study, bile acid was suggested to promote EPC-induced angiogenesis in HCC tumors. The bile acid level was positively related to the VEGFR-2 and CD34 expression levels in tumor and matched adjacent tissues. Moreover, the number of EPCs was decreased in the high bile acid group in the peripheral blood of patients with HCC. A possible explanation for this phenomenon is that EPCs and CPCs may be activated by bile acid, thus translocating to adjacent tissues and stimulating tumor progression (24). However, different types of bile acid may have various roles in HCC. For instance, Wang et al (22) showed that bile acid induced tumor cell survival and chemoresistance in HCC. Additionally, the interaction between the enterohepatic circulation of bile acid and intestinal flora complicates the role of bile acid in HCC. For example, Yamada et al (18) demonstrated that bile acid was regulated by gut microbiota and promoted HCC development. This should be further investigated in future studies.

The present study has some limitations. EPC-induced angiogenesis should be confirmed via the merged imaging of proliferation, stem cell and endothelial markers, such as BrdU, CD34 and VEGFR-2 using confocal immunofluorescence. Furthermore, the results would be more reliable if tissue and blood samples were derived from the same group of patients. The effects and mechanism of bile acid on EPCs and angiogenesis also require further investigation using primary cells in vitro and in vivo.

In conclusion, the present study demonstrated that bile acid promoted VEGFR-2 and CD34 expression induced by EPCs in $\mathrm{HCC}$, and that these two markers were expressed at higher levels in tumor tissues compared with in matched adjacent tissues. Moreover, it was indicated that VEGFR-2 and CD34 expression levels were both negatively related to OS.

\section{Acknowledgements}

Not applicable. 


\section{Funding}

The present study was supported by the Shanghai Municipal Education Commission (grant no. 2019 Technology Education-01-8), the Shanghai Pudong New Area Municipal Commission of Health and Family Planning Funding (grant nos. PW2015D-3 and PWZXQ2017-06) and in part by the National Nature Science Foundation of China (grant no. 81971223).

\section{Availability of data and materials}

The datasets used and/or analyzed during the present study are available from the corresponding author on reasonable request.

\section{Authors' contributions}

WFY, JLC and YFJ developed the experimental concept and design of the study. LW analyzed the clinicopathological characteristic factors and conducted the flow cytometry. Tissue microarray, immunohistochemical staining and statistical analyses were performed by JLC. RL conducted the immunohistochemical staining evaluation. JLC, WFY and YFJ drafted and revised the manuscript. All authors have read and approved the final manuscript.

\section{Ethics approval and consent to participate}

The present study was approved by the Committee of Research Ethical Research atEHBH (approval no. EHBHKY2018-1-019), and prior patient written informed consent was obtained from all enrolled patients.

\section{Patient consent for publication}

Not applicable.

\section{Competing interests}

The authors declare that they have no competing interests.

\section{References}

1. St Croix BD, Rak JW and Kerbel RS: Consequences of angiogenesis for tumor progression, metastasis and cancer therapy. Anticancer Drugs 6: 3-18, 1995.

2. Hervey-Jumper SL, Garton HJL, Lau D, Altshuler D, Quint DJ, Robertson PL, Muraszko KM and Maher CO: Differences in vascular endothelial growth factor receptor expression and correlation with the degree of enhancement in medulloblastoma. J Neurosurg Pediatr 14: 121-128, 2014.

3. Li S, Xu HX, Wu CT, Wang WQ, Jin W, Gao HL, Li H, Zhang SR, $\mathrm{Xu} \mathrm{JZ}$, Qi ZH, et al: Angiogenesis in pancreatic cancer: Current research status and clinical implications. Angiogenesis 22: 15-36, 2019.

4. Folkman $\mathrm{J}$ : What is the evidence that tumors are angiogenesis dependent. J Natl Cancer Inst 82: 4-6, 1990.

5. Viallard $C$ and Larrivee B: Tumor angiogenesis and vascular normalization: Alternative therapeutic targets. Angiogenesis 20: 409-426, 2017

6. Peters EB: Endothelial progenitor cells for the vascularization of engineered tissues. Tissue Eng Part B Rev 24: 1-24, 2018.

7. Mandraffino G and Saitta A: Endothelial and circulating progenitor cells: Between diseases and therapies. Curr Med Chem 25: 4476-4477, 2018.
8. Zhou M, Wang H, Zeng X, Yin P, Zhu J, Chen W, Li X, Wang L, Wang L, Liu Y, et al: Mortality, morbidity, and risk factors in China and its provinces, 1990-2017: A systematic analysis for the global burden of disease study 2017. Lancet 394: 1145-1158, 2019.

9. Zhu AX, Duda DG, Sahani DV and Jain RK: HCC and angiogenesis: Possible targets and future directions. Nat Rev Clin Oncol 8: 292-301, 2011.

10. Rafii S and Lyden D: Cancer. A few to flip the angiogenic switch Science 319: 163-164, 2008

11. Poon RT, Fan ST, Lo CM, Liu CL, Lam CM, Yuen WK, Yeung C and Wong J: Extended hepatic resection for hepatocellular carcinoma in patients with cirrhosis: Is it justified? Ann Surg 236: 602-611, 2002.

12. Ho JW, Pang RW, Lau C, Sun CK, Yu WC, Fan ST and Poon RT: Significance of circulating endothelial progenitor cells in hepatocellular carcinoma. Hepatology 44: 836-843, 2006.

13. Sieghart W, Fellner S, Reiberger T, Ulbrich G, Ferlitsch A, Wacheck V and Peck-Radosavljevic M: Differential role of circulating endothelial progenitor cells in cirrhotic patients with or without hepatocellular carcinoma. Dig Liver Dis 41: 902-906, 2009.

14. Yu D, Sun X, Qiu Y, Zhou J, Wu Y, Zhuang L, Chen J and Ding Y: Identification and clinical significance of mobilized endothelial progenitor cells in tumor vasculogenesis of hepatocellular carcinoma. Clin Cancer Res 13: 3814-3824, 2007.

15. Shaked Y, Henke E, Roodhart JM, Mancuso P, Langenberg MH, Colleoni M, Daenen LG, Man S, Xu P, Emmenegger U, et al: Rapid chemotherapy-induced acute endothelial progenitor cell mobilization: Implications for antiangiogenic drugs as chemosensitizing agents. Cancer Cell 14: 263-273, 2008.

16. Li CX, Shao Y, Ng KT, Liu XB, Ling CC, Ma YY, Geng W, Fan ST, Lo CM and Man K: FTY720 suppresses liver tumor metastasis by reducing the population of circulating endothelial progenitor cells. PLoS One 7: e32380, 2012.

17. Lee ES, Han EM, Kim YS, Shin BK, Kim CH, Kim HK, Won NH, Yeom BW, Kim I and Leong ASY: Occurrence of c-kit+ tumor cells in hepatitis B virus-associated hepatocellular carcinoma. Am J Clin Pathol 124: 31-36, 2005.

18. Yamada S, Takashina Y, Watanabe M, Nagamine R, Saito Y, Kamada $\mathrm{N}$ and Saito H: Bile acid metabolism regulated by the gut microbiota promotes non-alcoholic steatohepatitis-associated hepatocellular carcinoma in mice. Oncotarget 9: 9925-9939, 2018.

19. Liu N, Feng H, Lv Y, Liu Q, Deng J, Xia Y, Guo C and Zhou Y: Role of bile acids in the diagnosis and progression of liver cirrhosis: A prospective observational study. Exp Ther Med 18: 4058-4066, 2019.

20. Wu WB, Chen YY, Zhu B, Peng XM, Zhang SW and Zhou ML: Excessive bile acid activated NF-kappa B and promoted the development of alcoholic steatohepatitis in farnesoid $\mathrm{X}$ receptor deficient mice. Biochimie 115: 86-92, 2015.

21. Liao M, Zhao J Wang T, Duan J, Zhang Y and Deng X: Role of bile salt in regulating Mcl-1 phosphorylation and chemoresistance in hepatocellular carcinoma cells. Mol Cancer 10: 44, 2011.

22. Wang C, Yang M, Zhao J, Li X, Xiao X, Zhang Y, Jin X and Liao M: Bile salt (glycochenodeoxycholate acid) induces cell survival and chemoresistance in hepatocellular carcinoma. J Cell Physiol 234: 10899-10906, 2019.

23. Cho JG, Lee JH, Hong SH, Lee HN, Kim CM, Kim SY, Yoon KJ, Oh BJ, Kim JH, Jung SY, et al: Tauroursodeoxycholic acid, a bile acid, promotes blood vessel repair by recruiting vasculogenic progenitor cells. Stem Cells 33: 792-805, 2015.

24. Takahashi T, Kalka C, Masuda H, Chen D, Silver M, Kearney M, Magner M, Isner JM and Asahara T: Ischemia- and cytokine-induced mobilization of bone marrow-derived endothelial progenitor cells for neovascularization. Nat Med 5: 434-438, 1999.

25. Rafii S: Circulating endothelial precursors: Mystery, reality, and promise. J Clin Invest 105: 17-19, 2000.

26. Carmeliet P and Jain R: Angiogenesis in cancer and other diseases. Nature 407: 249-257, 2000.

27. Dvorak HF: Vascular permeability factor/vascular endothelial growth factor: A critical cytokine in tumor angiogenesis and a potential target for diagnosis and therapy. J Clin Oncol 20: 4368-4380, 2002.

28. Ferrara N, Hillan KJ, Gerber HP and Novotny W: Discovery and development of bevacizumab, an anti-VEGF antibody for treating cancer. Nat Rev Drug Discov 3: 391-400, 2004.

29. Hamanishi J, Mandai M, Iwasaki M, Okazaki T, Tanaka Y, Yamaguchi K, Higuchi T, Yagi H, Takakura K, Minato N, et al: Programmed cell death 1 ligand 1 and tumor-infiltrating CD8+ $\mathrm{T}$ lymphocytes are prognostic factors of human ovarian cancer. Proc Natl Acad Sci USA 104: 3360-3365, 2007. 
30. Zhao S, Wang M, Yang Z, Tan K, Zheng D, Du X and Liu L: Comparison between child-pugh score and albumin-bilirubin grade in the prognosis of patients with $\mathrm{HCC}$ after liver resection using time-dependent ROC. Ann Transl Med 8: 539, 2020.

31. Glaser S, Onori P Gaudio E, Ueno Y, Pannarale L, Franchitto A, Francis H, Mancinelli R, Carpino G, Venter J, et al: Taurocholic acid prevents biliary damage induced by hepatic artery ligation in cholestatic rats. Dig Liver Dis 42: 709-717, 2010.

32. Nakamura K, Zen Y, Sato Y, Kozaka K, Matsui O, Harada K and Nakanuma Y: Vascular endothelial growth factor, its receptor Flk-1, and hypoxia inducible factor-1alpha are involved in malignant transformation in dysplastic nodules of the liver. Hum Pathol 38: 1532-1546, 2007.

33. Iavarone M, Lampertico P, Iannuzzi F, Manenti E, Donato MF, Arosio E, Bertolini F, Primignani M, Sangiovanni A and Colombo M Increased expression of vascular endothelial growth factor in small hepatocellular carcinoma. J Viral Hepat 14: 133-139, 2007.

34. Jia JB, Zhuang PY, Sun HC, Zhang JB, Zhang W, Zhu XD, Xiong YQ, Xu HX and Tang ZY: Protein expression profiling of vascular endothelial growth factor and its receptors identifies subclasses of hepatocellular carcinoma and predicts survival. J Cancer Res Clin Oncol 135: 847-854, 2009.

35. Huang J, Zhang X, Tang Q, Zhang F, Li Y, Feng Z and Zhu J: Prognostic significance and potential therapeutic target of VEGFR2 in hepatocellular carcinoma. J Clin Pathol 64: 343-348, 2011.

36. Llovet JM, Ricci S, Mazzaferro V, Hilgard P, Gane E, Blanc JF, de Oliveira AC, Santoro A, Raoul JL, Forner A, et al: Sorafenib in advanced hepatocellular carcinoma. N Engl J Med 359: 378-390, 2008

37. Wang H, Chen K, Niu G and Chen X: Site-specifically biotinylated VEGF(121) for nearinfrared fluorescence imaging of tumor angiogenesis. Mol Pharm 6: 285-294, 2009.
38. Giannelli G, Sgarra C, Porcelli L, Azzariti A, Antonaci S and Paradiso A: EGFR and VEGFR as potential target for biological therapies in HCC cells. Cancer Lett 262: 257-264, 2008.

39. Tsuji N, Ishiguro S, Sasaki Y and Kudo M: CD34 expression in noncancerous liver tissue predicts multicentric recurrence of hepatocellular carcinoma. Dig Dis 31: 467-471, 2013.

40. Yang ZF and Poon RT: Vascular changes in hepatocellular carcinoma. Anat Rec (Hoboken) 291: 721-734, 2008.

41. Segatelli V, de Oliveira EC, Boin IF, Ataide EC and Escanhoela CA Evaluation and comparison of microvessel density using the markers CD34 and CD105 in regenerative nodules, dysplastic nodules and hepatocellular carcinoma. Hepatol Int 8: 260-265, 2014.

42. Zhu X, Zhou H, Luo J, Cui Y, Li H, Zhang W, Fang F, Li Q and Zhang T: Different but synergistic effects of bone marrow-derived VEGFR2+ and VEGFR2-CD45+ cells during hepatocellular carcinoma progression. Oncol Lett 13: 63-68, 2017.

43. Fürstenberger G, von Moos R, Lucas R, Thürlimann B, Senn HJ, Hamacher J and Boneberg EM: Circulating endothelial cells and angiogenic serum factors during neoadjuvant chemotherapy of primary breast cancer. Br J Cancer 94: 524-531, 2006.

44. Zahran AM, Abdel-Rahim MH, Refaat A, Sayed M, Othman MM, Khalak LMR and Hetta HF: Circulating hematopoietic stem cells, endothelial progenitor cells and cancer stem cells in hepatocellular carcinoma patients: Contribution to diagnosis and prognosis. Acta Oncol 59: 33-39, 2020.

This work is licensed under a Creative Commons Attribution-NonCommercial-NoDerivatives 4.0 International (CC BY-NC-ND 4.0) License. 